\title{
Integrated OMICS guided engineering of biofuel butanol-tolerance in photosynthetic Synechocystis sp. PCC 6803
}

Hongji Zhu ${ }^{1,2}$, Xiaoyue Ren ${ }^{1,2}$, Jiangxin Wang ${ }^{1,2}$, Zhongdi Song ${ }^{1,2}$, Mengliang Shi ${ }^{1,2}$, Jianjun Qiao ${ }^{1,2}$, Xiaoxu Tian ${ }^{1,2}$, Jie Liu ${ }^{1,2}$, Lei Chen ${ }^{1,2^{*}}$ and Weiwen Zhang ${ }^{1,2^{2}}$

\begin{abstract}
Background: Photosynthetic cyanobacteria have been recently proposed as a 'microbial factory' to produce butanol due to their capability to utilize solar energy and $\mathrm{CO}_{2}$ as the sole energy and carbon sources, respectively. However, to improve the productivity, one key issue needed to be addressed is the low tolerance of the photosynthetic hosts to butanol.

Results: In this study, we first applied a quantitative transcriptomics approach with a next-generation RNA sequencing technology to identify gene targets relevant to butanol tolerance in a model cyanobacterium Synechocystis sp. PCC 6803. The results showed that 278 genes were induced by the butanol exposure at all three sampling points through the growth time course. Genes encoding heat-shock proteins, oxidative stress related proteins, transporters and proteins involved in common stress responses, were induced by butanol exposure. We then applied GC-MS based metabolomics analysis to determine the metabolic changes associated with the butanol exposure. The results showed that 46 out of 73 chemically classified metabolites were differentially regulated by butanol treatment. Notably, 3-phosphoglycerate, glycine, serine and urea related to general stress responses were elevated in butanol-treated cells. To validate the potential targets, we constructed gene knockout mutants for three selected gene targets. The comparative phenotypic analysis confirmed that these genes were involved in the butanol tolerance.
\end{abstract}

Conclusion: The integrated OMICS analysis provided a comprehensive view of the complicated molecular mechanisms employed by Synechocystis sp. PCC 6803 against butanol stress, and allowed identification of a series of potential gene candidates for tolerance engineering in cyanobacterium Synechocystis sp. PCC 6803.

Keywords: Butanol, Tolerance, Transcriptomics, Metabolomics, Synechocystis

\section{Background}

Due to its high energy content and superior chemical properties such as low volatility and corrosiveness, and its compatibility with the existing fuel storage and distribution infrastructure, butanol has been proposed as a good candidate for next-generation transportation biofuel $[1,2]$. Traditionally, bio-butanol can be produced by anaerobic Gram-positive bacteria, such as Clostridium acetobutylicum through a so-called acetone-butanol-ethanol

\footnotetext{
* Correspondence: Ichen@tju.edu.cn

'Laboratory of Synthetic Microbiology, School of Chemical Engineering \& Technology, Tianjin University, Tianjin 300072, P.R. China

${ }^{2}$ Key Laboratory of Systems Bioengineering, Ministry of Education, Tianjin
} 300072, P.R. China
(ABE) fermentation process [3,4]. Although significant improvements have been made in the past decades to increase efficiency of the ABE process through a combination of strain screening, genetic engineering and process optimization [5-8], butanol production from the fermentation processes is still not competitive economically. As one of the alternatives, photosynthetic cyanobacteria have recently attracted significant attention as a 'microbial factory' to produce biofuels and chemicals due to their capability to utilize solar energy and $\mathrm{CO}_{2}$ as the sole energy and carbon sources, respectively $[9,10]$. Recent synthetic biology efforts have led to successful production of $n$-butanol, isobutyraldehyde and

\section{Biomed Central}


isobutanol in cyanobacterium Synechococcus elongatus PCC $7942[11,12]$, demonstrating the potentials of using engineered photosynthetic microbes for large-scale production of butanol or other biofuel products in the future.

Currently, the butanol production by the synthetic cyanbacterial systems is at a level of a few dozen or hundred milligrams per liter [11], much lower than the native Clostridium or even synthetic Escherichia coli systems [13-15]. To improve productivity, one of the key issues needed to be addressed is the low tolerance of the photosynthetic hosts to butanol $[16,17]$. The tolerance mechanism of native Clostridium strains to butanol has been well-studied [16-19]. For example, analysis of butanol tolerant transposon-insertion mutants of Clostridium beijerinckii NCIMB 8052 have led to the discovery that butanol-tolerance is associated with reduced activity of the enzyme, glycerol dehydrogenase [20]. Recently a functionally unknown protein (encoded by SMB_G1518) with a hypothetical alcohol interacting domain was also found negatively related to butanol tolerance [21]. In E. coli, a global transcription factor cyclic AMP receptor protein (CRP) was also engineered for increasing butanol tolerance [22]. However, currently information related to biofuel tolerance in cyanobacteria is very limited.

Recently various genome-wide approaches, such as genomic library enrichment and whole-genome sequencing of tolerant mutants were also employed to identify genes conferring enhanced tolerance to $n$-butanol in $E$. coli $[23,24]$. The results showed that microbes tend to employ multiple and synergistic resistance mechanisms in dealing with a single stress [17], and to fully interpret the complicated and synergistic tolerance mechanism, genome-wide based analytical approaches are necessary [25]. In a previous study, we investigated responses of Synechocystis sp. PCC 6803 (hereafter Synechocystis) to butanol using an iTRAQ - LC-MS/MS based proteomics, the results identified 303 proteins differentially regulated by butanol [26]. To further decipher responses at transcript and metabolite levels, and to identify gene targets relevant to butanol tolerance, in this study, we applied an integrated approach coupling quantitative RNA-seq transcriptomics approach, quantitative reverse-transcript PCR (qRT-PCR) and GC-MS based metabolomics to analyze cellular responses of Synechocystis to butanol exposure. The transcriptomic result revealed very similar response patterns as those identified by the previous proteomic analysis that multiple resistance mechanisms may be utilized in coping with butanol stress in Synechocystis [26]; and the metabolomic analysis showed that 46 chemically classified metabolites were differentially regulated by butanol treatment, including 3-phosphoglycerate, glycine and urea which were elevated in butanol-treated cells. The integrated analysis led to the identification of a series of potential gene targets and pathways for tolerance engineering, we then constructed gene knockout mutants for three selected butanol-induced genes, sll0690, slr0947 and $\operatorname{sir1295}$, and comparative phenotype analyses showed that their disruptions led to increased sensitivity to butanol, suggesting the gene targets identified can be used for engineering butanol tolerance in Synechocystis.

\section{Results and discussion}

\section{Overview of RNA-Seq transcriptomics analysis}

To make the transcriptomics data comparable with previous proteomics data, we used the identical sampling conditions for transcriptomics as our previous proteomic analysis [26]. As described previously, Synechocystis was grown in BG11 supplemented with $0.20 \%(v / v)$ butanol and cell samples of both control and butanol treatment were collected by centrifugation $\left(8,000 \times g\right.$ for $10 \mathrm{~min}$ at $\left.4^{\circ} \mathrm{C}\right)$ at $24 \mathrm{~h}, 48 \mathrm{~h}$ and $72 \mathrm{~h}$, corresponded to middle-exponential, exponential-stationary transition and stationary phases of the cell growth, respectively.

A total of 79.5-million raw sequencing reads was obtained from the RNA-seq transcriptomics analysis of six samples, with average reads of 13.2-million reads. After a two-step standard data filtering process, first to eliminate reads with low-quality bases (such as multiple $\mathrm{N}$ ) and reads shorter than $20 \mathrm{bp}$, and then to eliminate sequence reads mapped to non-coding RNA of Synechocystis, a total of 27.5-million qualified mRNA-based sequence reads were identified (Table 1). The qualified sequence reads have an average genome mapping ratio of $66.4 \%$. To assess the analytical reproducibility between biological replicates, we collected two biological replicates for butanol treated samples at $72 \mathrm{~h}$, and plotted them using the normalized Reads Per Kilobase of Gene per Million Mapped Reads (RPKM) values, the result showed a correlation coefficient around 0.991 (Figure 1), indicating the overall good quality of RNA-sequencing based transcriptomics technology. The sequence reads matched to all 3189 coding genes in Synechocystis genome (data not shown), suggesting excellent sequencing depth and overall transcript coverage.

Using a strict criterion of 1.5 -fold change at all three time points (i.e., 24, 48 and $72 \mathrm{~h}$ ), we determined that 278 genes were induced upon butanol exposure, out of which 70 important genes with known functional categories were listed in Table 2. Functional category analysis of the induced genes showed that the most affected functional categories were "hypothetical proteins", representing a total of more than $40 \%$ of all the up-regulated genes, consistent with the fact that nearly half of the genes in the Synechocystis genome are still annotated as hypothetical up to now [27]. Based on their expression level and regulation patterns by butanol, a subset of 10 genes was randomly selected for quantitative RT-PCR validation. Comparative RT-PCR analysis was performed for the genes between the butanol-treated sample and control 
Table 1 Statistics of RNA-Seq transcriptomics analysis

\begin{tabular}{ccccc}
\hline Sample ID & Raw sequence reads & Qualified mRNA reads & Genome mapped reads & Mapping ratio \\
\hline C242 & $15,535,317$ & $5,552,572$ & $3,177,168$ & $57.22 \%$ \\
C483 & $9,013,667$ & $2,331,738$ & $1,784,966$ & $76.55 \%$ \\
C722 & $8,986,367$ & $3,026,360$ & $2,455,571$ & $81.14 \%$ \\
B241 & $9,175,893$ & $2,947,480$ & $1,755,209$ & $59.55 \%$ \\
B483 & $13,434,402$ & $4,733,896$ & $3,005,487$ & $63.49 \%$ \\
B724 & $23,330,644$ & $8,945,794$ & $5,430,235$ & $60.70 \%$ \\
\hline
\end{tabular}

at $48 \mathrm{~h}$. The results showed very similar trends between qRT-PCR and RNA-Seq transcriptomics data (Table 3), suggesting a good quality of RNA-seq data.

\section{Potential gene targets related to butanol tolerance}

Our previous proteomic analysis found that the Synechocystis cells employed a combination of approaches to cope with butanol stress, and the responses included an induced common stress response, modifications of cell envelope, and induction of multiple transporters and signal transduction proteins against butanol stress [26]. Transcriptomic analysis showed very similar responses:

i. Heat-shock and general stress proteins: early analysis of butanol tolerance in both native and unnatural producing microorganisms showed that heat-shock proteins were relevant to tolerance $[7,17]$. Our quantitative proteomics found that DnaJ1 (Slr0093) was significantly induced at $48 \mathrm{~h}$ after butanol treatment [26]. At transcriptional level, we found that four genes involved in heat shock and general stress responses were induced (i.e., slr0093, sll1988, sll1388 and slr1854). In addition, slr1204 encoding a putative serine protease (HtrA) and slr0835

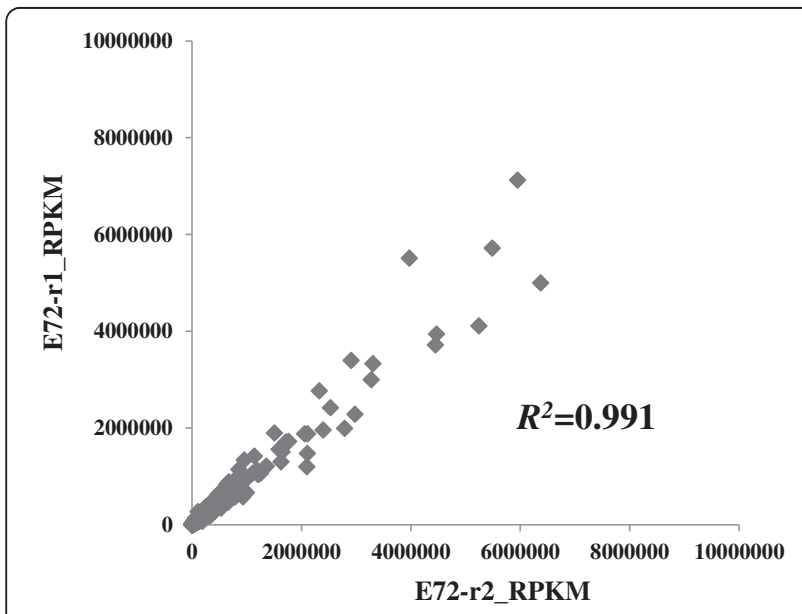

Figure 1 Reproducibility of RNA-seq transcriptomic analysis. Two biological replicates of butanol-treated samples were plotted. Normalized expression RPKM values were used. Correlation coefficient is indicated inside. encoding a MoxR protein homolog were also up-regulated significantly by butanol (Table 2). HtrA-type serine proteases participate in folding and degradation of aberrant proteins and in processing and maturation of native proteins, and $h t r A$ mutation often conferred a pleiotropic phenotype that can include high sensitivity to various stress [28]. The MoxR family AAA+ proteins are ubiquitous proteins that employ the energy obtained from ATP hydrolysis to remodel proteins, DNA or RNA. Early studies have showed that some members of this protein group can potentially function as molecular chaperones involved in the assembly of protein complexes [29], and be involved in stress resistance and virulence in Francisella tularensis [30].

ii. Oxidative stress response: early studies showed that solvent like ethanol or butanol can challenge cells by causing increased production of highly reactive oxygen species (ROS) [31]. Transcriptomic analysis found that butanol induced expression of $\operatorname{sir} 1828$ and sll0248 genes encoding a petF-like ferredoxin and a flavodoxin protein (Table 2), respectively, consistent with the up-regulation of these two proteins in proteomics dataset. In addition, transcriptomic analysis showed that other genes involved in oxidative stress response, such as ssl2250 encoding a bacterioferritin-associated ferredoxin, slr1846 encoding a putative monothiol glutaredoxin and slr1795 encoding a peptide methionine sulfoxide reductase were also up-regulated (Table 2). Recent study showed that bacterioferritin comigratory proteins, along with glutathione peroxidasereductase, were responsible for detoxification of bentazone-derived peroxide in a $S$. elongatus PCC7942 mutant Mu2 [32]. Monothiol glutaredoxins was found with roles in actin cytoskeleton remodeling and cellular defenses against oxidative stress caused by ROS accumulation in Saccharomyces cerevisiae and

Schizosaccharomyces pombe [33,34]. In addition, monothiol glutaredoxin (Slr1846) was found up-regulated by ethanol in Synechocystis [35]. Specific modifications of certain amino acid side chains are common during oxidative stress. Cysteine 
Table 2 Important gene tragets induced by butanol

\begin{tabular}{|c|c|c|c|c|}
\hline Gene ID & $\begin{array}{l}\text { Butanol vs. Control } \\
\text { at } 24 \mathrm{~h}\end{array}$ & $\begin{array}{l}\text { Butanol vs. Control } \\
\text { at } 48 \mathrm{~h}\end{array}$ & $\begin{array}{l}\text { Butanol vs. Control } \\
\text { at } 72 \mathrm{~h}\end{array}$ & Description \\
\hline \multicolumn{5}{|c|}{ Cell envelope } \\
\hline sll0034 & 2.52 & 1.54 & 1.86 & D, D-carboxypeptidase \\
\hline sll0286 & 2.33 & 1.90 & 1.55 & Uncharacterized N-acetyltransferase \\
\hline sll0886 & 1.88 & 1.78 & 2.79 & $\begin{array}{l}\text { UDP-N-acetylglucosamme-peptide } \\
\text { N-acetylglucosammyltransferase- }\end{array}$ \\
\hline s/11053 & 3.52 & 4.00 & 12.12 & Membrane fusion protein mtrc precursor, putative \\
\hline s/11395 & 1.91 & 2.61 & 1.54 & dTDP-6-6-deoxy-L-mannose-dehydrogenase \\
\hline sll2010 & 1.60 & 1.78 & 2.89 & UDP-N-acetylmuramoylalanine-D-glutamate ligase \\
\hline slr0528 & 2.52 & 1.91 & 2.45 & $\begin{array}{l}\text { UDP-N-acetylmuramoylalanyl-D-glutamate-2, } \\
\text { 6-diaminopimelate ligase }\end{array}$ \\
\hline slr0993 & 1.75 & 2.33 & 4.21 & Putative peptidase \\
\hline slr1166 & 2.86 & 1.68 & 2.36 & UDP-glucose:tetrahydrobiopterin glucosyltransferase \\
\hline slr1196 & 4.07 & 1.91 & 2.74 & Periplasmic protein, function unknown \\
\hline $\operatorname{sir} 1744$ & 1.89 & 1.92 & 2.42 & $\mathrm{~N}$-acetylmuramoyl-L-alanine amidase, periplasmic protein \\
\hline slr2015 & 3.56 & 4.15 & 2.39 & Type 4 pilin-like protein, essential for motility \\
\hline slr2016 & 4.40 & 1.71 & 1.71 & Type 4 pilin-like protein, essential for motility \\
\hline \multicolumn{5}{|c|}{ Central intermediary metabolism } \\
\hline sll0646 & 4.03 & 1.87 & 1.96 & Guanylyl cyclase \\
\hline slr0288 & 1.65 & 2.28 & 2.58 & Glutamate-ammonia ligase \\
\hline slr0899 & 2.19 & 2.75 & 2.50 & Cyanate lyase \\
\hline slr0940 & 3.33 & 1.96 & 4.21 & Zeta-carotene desaturase \\
\hline slr1254 & 1.73 & 1.76 & 4.43 & Phytoene dehydrogenase (phytoene desaturase) \\
\hline slr1877 & 6.00 & 3.15 & 3.75 & 2-hydroxyhepta-2, 4-diene-1, 7-dioate isomerase \\
\hline \multicolumn{5}{|c|}{ Common stress response } \\
\hline sll0248 & 3.60 & 3.67 & 1.86 & Flavodoxin \\
\hline s/11388 & 3.21 & 1.58 & 1.82 & Universal stress protein \\
\hline s/11988 & 1.90 & 1.53 & 1.81 & 33 kDa chaperonin \\
\hline slr0093 & 2.61 & 1.53 & 2.61 & DnaJ protein, molecular chaperone \\
\hline $\operatorname{sir} 1795$ & 2.43 & 1.71 & 2.16 & Peptide methionine sulfoxide reductase \\
\hline slr1828 & 3.38 & 3.33 & 11.00 & Ferredoxin, petF-like protein \\
\hline slr1846 & 1.53 & 2.25 & 4.71 & Uncharacterized monothiol glutaredoxin \\
\hline slr1854 & 4.09 & 1.59 & 4.38 & General stress protein 18 (gsp17) \\
\hline slr2047 & 2.06 & 1.65 & 1.62 & Phosphate starvation-inducible protein \\
\hline ss 12250 & 6.00 & 2.00 & 5.00 & Bacterioferritin-associated ferredoxin \\
\hline \multicolumn{5}{|c|}{ Protein fate } \\
\hline sll0616 & 4.19 & 1.88 & 3.54 & Preprotein translocase SecA subunit \\
\hline sll0716 & 3.50 & 3.00 & 1.83 & Probable signal peptidase $\mathrm{I}-1$ \\
\hline slr0835 & 1.87 & 2.17 & 6.92 & MoxR protein homolog \\
\hline slrog94 & 2.22 & 1.62 & 2.30 & Octanoyltransferase \\
\hline slr1046 & 1.86 & 1.75 & 1.50 & Putative TatA protein \\
\hline slr1204 & 4.18 & 2.63 & 5.57 & Putative serine protease $\mathrm{HtrA}$ \\
\hline slr1331 & 2.94 & 2.26 & 3.98 & Periplasmic processing protease \\
\hline ssr3307 & 1.76 & 1.63 & 2.04 & Preprotein translocase SecG subunit \\
\hline
\end{tabular}


Table 2 Important gene tragets induced by butanol (Continued)

\begin{tabular}{|c|c|c|c|c|}
\hline \multicolumn{5}{|c|}{ Regulatory functions } \\
\hline sll0043 & 3.20 & 3.20 & 2.21 & Positive phototaxis histidine kinase \\
\hline sll0690 & 5.00 & 1.57 & 6.00 & Probable transcription regulator \\
\hline slr0640 & 2.28 & 1.86 & 2.20 & Two-component sensor histidine kinase \\
\hline slr0780 & 1.84 & 1.70 & 2.33 & Transcriptional repressor NrdR \\
\hline slr0947 & 3.18 & 2.38 & 5.44 & $\begin{array}{l}\text { Response regulator for energy transfer from } \\
\text { phycobilisomes to photosystems }\end{array}$ \\
\hline slr1037 & 3.63 & 2.00 & 3.33 & Two-component response regulator CheY subfamily \\
\hline slr1042 & 3.60 & 2.45 & 1.72 & Two-component response regulator CheY subfamily \\
\hline slr1414 & 1.54 & 1.67 & 1.66 & Two-component sensor histidine kinase \\
\hline slr1531 & 3.00 & 1.83 & 1.55 & Signal recognition particle protein \\
\hline slr1805 & 1.53 & 3.81 & 4.66 & Two-component sensor histidine kinase \\
\hline ss10707 & 2.67 & 1.93 & 2.78 & Nitrogen regulatory protein P-\|I \\
\hline \multicolumn{5}{|c|}{ Storage compound biosynthesis } \\
\hline slr1993 & 8.75 & 1.76 & 4.79 & PHA-specific beta-ketothiolase \\
\hline slr1994 & 32.00 & 11.50 & 4.86 & PHA-specific acetoacetyl-CoA reductase \\
\hline slr2002 & 3.52 & 2.09 & 2.57 & Cyanophycin synthetase \\
\hline \multicolumn{5}{|c|}{ Transport and binding proteins } \\
\hline sll0374 & 1.65 & 1.90 & 2.83 & Urea transport system ATP-binding protein \\
\hline sll0689 & 2.21 & 1.63 & 3.28 & $\mathrm{Na}+/ \mathrm{H}+$ antiporter \\
\hline sll0759 & 3.11 & 1.56 & 6.87 & ABC transporter ATP-binding protein \\
\hline sll1041 & 3.74 & 2.50 & 3.43 & Similar to sulfate transport ATP-binding protein CysA \\
\hline s/11154 & 1.76 & 2.80 & 3.98 & NorA \\
\hline s/17164 & 6.60 & 1.50 & 1.60 & Uncharacterized transporter \\
\hline s/l1428 & 32.00 & 2.00 & 7.00 & Probable sodium-dependent transporter \\
\hline s/17450 & 2.89 & 3.98 & 5.27 & $\begin{array}{l}\text { Nitrate/nitrite transport system } \\
\text { substrate-binding protein }\end{array}$ \\
\hline sll1451 & 2.52 & 1.73 & 5.97 & Nitrate/nitrite transport system permease protein \\
\hline s/17452 & 1.98 & 1.66 & 3.12 & Nitrate/nitrite transport system ATP-binding protein \\
\hline s/l1481 & 3.14 & 1.66 & 3.38 & ABC-transporter membrane fusion protein \\
\hline s/17482 & 3.30 & 1.51 & 2.57 & $A B C$ transporter permease protein \\
\hline s/11623 & 2.15 & 1.56 & 1.91 & ABC transporter ATP-binding protein \\
\hline slr1248 & 2.57 & 2.63 & 3.00 & $\begin{array}{l}\text { Phosphate transport system permease protein } \\
\text { PstC homolog }\end{array}$ \\
\hline slr1295 & 2.33 & 1.79 & 5.92 & Iron transport system substrate-binding protein \\
\hline$s \operatorname{lr} 1318$ & 1.50 & 2.50 & 1.77 & Iron (III) dicitrate transport system ATP-binding protein \\
\hline slr1515 & 2.56 & 1.61 & 3.47 & $\begin{array}{l}\text { Putative membrane protein required for } \\
\text { bicarbonate uptake }\end{array}$ \\
\hline$s / r 1729$ & 1.96 & 1.52 & 2.13 & Potassium-transporting P-type ATPase B chain \\
\hline slr2131 & 4.50 & 2.51 & 12.87 & RND multidrug efflux transporter \\
\hline
\end{tabular}


Table 3 Comparison of ratios derived from RNA-seq and from RT-PCR analysis for selective genes

\begin{tabular}{lccc}
\hline Gene ID & Description & RT-PCR ratio & RNA-Seq ratio \\
\hline sll0221 & Bacterioferritin comigratory protein & -1.18 & -1.87 \\
sll0248 & Flavodoxin & 1.31 & 3.67 \\
sll0629 & Photosystem I reaction center subunit Psak 2 & 1.05 & 1.11 \\
sll1327 & ATP synthase gamma chain & 1.29 & 1.10 \\
sll1734 & Hypothetical protein & 1.52 & 1.29 \\
sll1796 & Cytochrome c6 & 1.74 & 2.38 \\
slr0288 & Glutamate-ammonia ligase & 4.47 & 2.28 \\
slr0952 & Fructose-1,6-bisphosphatase class 1 & -1.52 & 1.36 \\
s/r1828 & Ferredoxin & 1.96 & 3.33 \\
slr1909 & NarL subfamily response regulator & 1.50 & 1.06 \\
\hline
\end{tabular}

and methionine both contain a sulfur atom in their side chains and are among the most easily oxidized amino acids. Methionine sulfoxides can be reduced back to the methionines by peptide methionine sulfoxide reductase (MSR), providing cells with a mechanism to repair proteins damaged by reactive oxygen species rather than having them degraded and then re-synthesizing them de novo [36]. Induction of the methionine sulfoxide reductase by oxidative stress has been found in anaerobic Desulfovibrio vulgaris, E. coli, S. cerevisiae and Synechocystis [35-38].

iii. Transporters: transcriptomics analysis identified 19 membrane transporters were up-regulated. Among them only two genes, sll0689 and slr1512 which were in the same operon with butanol-induced slr1515, were identified in the previous proteomics analysis [26]. Interestingly, the up-regulated transporters involved a wide range of putative substrates, including iron, $\mathrm{Na}^{+} / \mathrm{H}^{+}$, nitrate/nitrite, phosphate, sodium, potassium, urea, bicarbonate and sulfate (Table 2). Moreover, many of these transporters were induced at significantly high fold changes, such as slr2131 encoding a RND multidrug efflux transporter up-regulated 12.87 fold at $72 \mathrm{~h}$, and sll1428 encoding a probable sodium-dependent transporter up-regulated 32.0 folds. Other up-regulated genes included sll1697 which encodes a well-studied multidrug efflux pump NorA [39]. Exact functions of these transporters in butanol tolerance may worth further investigation.

iv. Protein translocation: Bacteria have two major protein translocation systems, one of which is catalyzed by the Sec-dependent protein translocation system, and another is the Twin-arginine (Tat) protein translocation system $[40,41]$. Our proteomic analysis showed that SecE protein (Ssl3335) of Sec-dependent translocation system and Tha4 protein (Slr1047) of the Tat translocation system were up-regulated by butanol. Trnascriptomic analysis showed that ssr3307 encoding a preprotein translocase SecG subunit, sll0616 encoding a preprotein translocase SecA subunit and slr1046 encoding a putative TatA protein, were up-regulated by butanol. Genes slr1046 and $\operatorname{slr} 1047$ were organized in the same operon. The results confirmed that enhanced protein translocation systems may be an important mechanism against butanol stress.

v. Cell envelope: Cell envelope is the important barrier in protecting cells. Consistent with proteomic results, our transcriptomic analysis also found that many genes involved in cell envelope function were up-regulated upon butanol exposure, such as sll2010 encoding UDP-N-acetylmuramoylalanine-D-glutamate ligase, slr0528 encoding UDP-N-acetylmuramoylalanylD-glutamate-2, 6-diaminopimelate ligase and sllo88 encoding UDP-N-acetylglucosamine-peptide n-acetylglucosaminyltransferase (Table 3). Their up-regulation was supposed to strengthen cell wall structure against butanol stress.

vi. Regulatory genes: Previous proteomic analysis showed that several signal transduction proteins involved in cell mobility (i.e. Che type) and nitrate induction, and repression of genes encoding nitrate respiration enzymes (i.e. NarL subfamily) were up-regulated by butanol [26]. Transcriptomics analysis identified 11 butanol-induced signal transduction genes. The induced genes included two Che type response regulators (i.e. slr1042, slr1037) and one putative phototaxis histidine kinase (sll0043) involved in cell mobility, and one gene (ssl0707) involved in nitrogen metabolism. Gene ssl0707 encodes a nitrogen regulatory protein P-II belonging to the NtcA regulon in cyanobacteria [42]. Although the transcriptomic results confirmed that regulation of cell mobility and nitrogen responses are important in combating butanol stress, none of 
regulatory genes/proteins was identified in both transciptomic and proteomic datasets, suggesting the complicity of signal transduction in Synechocystis, and also the insufficiency to use any single 'omics' approach to characterize the complexity of biological systems [25]. To compare the proteomic and transcriptomic datasets quantitatively, 11 common genes/proteins up-regulated in both transcriptomics and proteomics datasets were listed in Table 4. The results also showed the very similar trends of up-regulation. In our previous proteomic analysis, using a cutoff of 1.5 -fold change and a $p$-value less than 0.05 , we determined that 63 and 79 proteins were up-regulated between control and butanol treatments conditions at $24 \mathrm{~h}$ and $48 \mathrm{~h}$, respectively; among which 35 proteins were up-regulated at both time points [26]. Comparison of proteomic and transcriptomic datasets showed that among the 278 genes up-regulated by butanol, 17 induced genes also had their corresponding proteins up-regulated (Table 4), 10 genes had their corresponding proteins down-regulated, and 251 induced genes have their protein levels unchanged. The finding that a relatively low number of genes and proteins shared the same up-regulation patterns, was probably due to the fact we used highly strict criteria in determining induced genes (i.e., up-regulated at all three time points in this study). In spite of low correlation between the two datasets, the patterns of metabolic changes key to the butanol tolerance seemed similar, as described above for each of the functional categories.

One goal of the integrated OMICS analysis is to achieve a complete coverage of cellular molecules by using complementary techniques targeting different levels of information (i.e., RNA, protein or metabolites) [25]. In this study, our transcriptomic analysis also revealed new cellular responses which were not observed in the previous proteomic analysis [26]: i) Enhanced production of storage compounds: Polyhydroxyalkanoates (PHAs) are common carbon storage compounds that are accumulated during unbalanced growth conditions [43]. Two genes involved in PHA biosynthesis, slr1994 encoding a PHA-specific acetoacetyl-CoA reductase and slr1993 encoding a PHA-specific beta-ketothiolase were found up-regulated by butanol (Table 2). Cyanophycin is a non-ribosomally synthesized peptide, composed of arginine and aspartic acid, accumulates when cells are grown under all unbalanced nutrient conditions except nitrogen starvation, and has been considered as a primary nitrogen reserve compound in cyanobacteria [44]. Transcriptomic analysis showed that the key gene

Table 4 Quantitative comparison of transcriptomic and proteomic analyses *

\begin{tabular}{|c|c|c|c|c|c|c|}
\hline \multirow[t]{2}{*}{ Gene ID } & \multicolumn{3}{|c|}{ Transcriptomics analysis (fold change) } & \multicolumn{2}{|c|}{ Proteomics analysis (fold change) } & \multirow[b]{2}{*}{ Description } \\
\hline & $\begin{array}{l}\text { Butanol vs. } \\
\text { Control at } 24 \mathrm{~h}\end{array}$ & $\begin{array}{l}\text { Butanol vs. } \\
\text { Control at } 48 \mathrm{~h}\end{array}$ & $\begin{array}{c}\text { Butanol vs. } \\
\text { Control at } 72 \mathrm{~h}\end{array}$ & $\begin{array}{l}\text { Butanol vs. } \\
\text { Control at } 24 \mathrm{~h}\end{array}$ & $\begin{array}{c}\text { Butanol vs. } \\
\text { Control at } 48 \mathrm{~h}\end{array}$ & \\
\hline sll0135 & 1.64 & 1.61 & 2.51 & & 2.42 & 5'-methylthioadenosine phosphorylase \\
\hline $\operatorname{sir1390}$ & 1.83 & 1.62 & 2.74 & & 1.52 & Cell division protein FtsH \\
\hline sll1796 & 3.70 & 2.38 & 9.75 & 3.80 & 2.91 & Cytochrome C553 \\
\hline slr0093 & 2.61 & 1.53 & 2.61 & & 1.93 & DnaJ protein \\
\hline $\operatorname{sir} 1330$ & 3.18 & 2.11 & 5.69 & 1.86 & & F0F1 ATP synthase subunit epsilon \\
\hline $\operatorname{sir1828}$ & 3.38 & 3.33 & 11.00 & 2.09 & 1.66 & ferredoxin \\
\hline sll0248 & 3.60 & 3.67 & 1.86 & 1.59 & 6.26 & Flavodoxin FldA \\
\hline sll0335 & 1.64 & 4.33 & 1.75 & & 1.52 & Hypothetical protein \\
\hline sll0470 & 4.27 & 1.55 & 2.84 & & 1.67 & Hypothetical protein \\
\hline sll1618 & 1.63 & 2.71 & 1.86 & 1.53 & 1.67 & Hypothetical protein \\
\hline s/l1895 & 2.23 & 1.69 & 2.31 & & 1.59 & Hypothetical protein \\
\hline slr0643 & 2.13 & 1.69 & 2.25 & 1.52 & 1.88 & Hypothetical protein \\
\hline slr1046 & 1.86 & 1.75 & 1.50 & 1.57 & & Hypothetical protein \\
\hline ss 10242 & 2.63 & 2.53 & 2.47 & 1.79 & 1.66 & Hypothetical protein \\
\hline ss 10352 & 2.30 & 2.60 & 6.33 & 1.62 & 1.84 & Hypothetical protein \\
\hline s110689 & 2.21 & 1.63 & 3.28 & 1.70 & 1.93 & $\mathrm{Na} / \mathrm{H}+$ antiporter \\
\hline $\operatorname{sir} 1755$ & 1.97 & 1.85 & 3.44 & 1.56 & & $\begin{array}{l}\mathrm{NAD}(\mathrm{P}) \mathrm{H} \text {-dependent glycerol- } \\
\text { 3-phosphate dehydrogenase }\end{array}$ \\
\hline
\end{tabular}

\footnotetext{
* Proteomics data from Tian et al., (2012), in which only proteomes at 24 and $48 \mathrm{~h}$ were measured. The fold changes of proteomics data are average of replicates.
} 
involved in cyanophycin synthesis, slr2002 encoding cyanophycin synthetase was up-regulated by butanol (Table 2). Although PHA and cyanophycin accumulation has been reported for many natural stress conditions, it may worth further investigation how these pathways respond to butanol stress; ii) Enhanced carotenoid biosynthesis: three genes involved in carotenoid biosynthesis were up-regulated: slr1254 encoding phytoene desaturase, slr0940 encoding zeta-carotene desaturase and slr0899 encoding cyanate lyase (Table 2). The results were consistent with the increased photosynthetic activity of Synechocystis upon butanol stress [26]. Carotenoid biosynthesis has been found up-regulated by strong light in Synechococcus PCC7942 [45], and in stress-tolerant mutants of Haematococcus pluvialis [46]. The results provided further evidences that the integrated OMICS approach could be advantageous in revealing global cellular responses.

\section{Metabolomic signatures related to butanol response} GC-MS based metabolomic analysis was used to characterize the time-series metabolic responses of Synechocystis to butanol exposure, with unperturbed cultures as controls. Cell samples used for metabolomic analysis were collected at 24, 48 and $72 \mathrm{~h}$, respectively, the identical time points of sampling for transcriptomic analysis. Three biological replicates were collected for each time point and treatment, thereby yielding a total of 18 samples. The analysis showed that a total of 73 metabolites were chemically identified with great confidence. Although more metabolites were detected in butanol-treated samples $(70.4 \pm 2.74)$ than the control samples $(64.12 \pm 4.01)$, the number of metabolites identified varied only slightly within control or treatment bins, implying an overall good analytical quality. To further assess the reproducibility of GC-MS metabolomics, we analyzed three technical replicates of one selected sample, and the results showed that most of the metabolites were identified in technical replicates (Date not shown).

The score plot of principal component analysis (PCA) was applied to evaluate the similarities and differences between the 18 metabolomic profiles (Figure 2). The score plot revealed the following features: $i$ ) the samples with or without butanol treatment at different time points were distinctly separated, suggesting significant metabolic differences between samples; $i$ ) for the control samples, metabolic changes along the time courses were relatively small, as showed by the clustering patterns of 9 samples; and iii) when compared with controls, significant metabolic changes were observed for butanol-treated samples, especially for samples with 48 and $72 \mathrm{~h}$ butanol treatments. One of the butanol-treated biological replicates was slightly different from other two biological replicates at $48 \mathrm{~h}$ and $72 \mathrm{~h}$, probably due to the fact the long-term butanol treatment has caused significant cell aggregation [26], which increased the sample heterogeneity. Nevertheless, the overall similar response patterns can still be observed in these replicate samples according to their position in the score plot (Figure 2). Using a cutoff ratio of 1.5 fold between butanol-treated and control samples, and change in at least 5 out of 9 replicate ratios in any time point, we determined 46 metabolites were differentially regulated, in which 35, 41 and 38 metabolites were detected in 24, 48 and $72 \mathrm{~h}$, respectively (Table 5 ). Pattern analysis showed the 48 metabolites can be divided into at least 6 clusters according to their changes along the treatment time courses. For example, Cluster I included 7 metabolites upregulated in all three time points, while Cluster II included 7 metabolites up-regulated only in 48 and $72 \mathrm{~h}$ after butanol exposure (Table 5).

Metabolomic analysis has identified several metabolites induced by butanol treatment, including 3-phosphoglycerate (3-PG) and glycerol 1-phosphate induced significantly in all three time points, serine induced at 24 and $48 \mathrm{~h}$, and glycine induced at 48 and $72 \mathrm{~h}$ after butanol exposure, respectively.

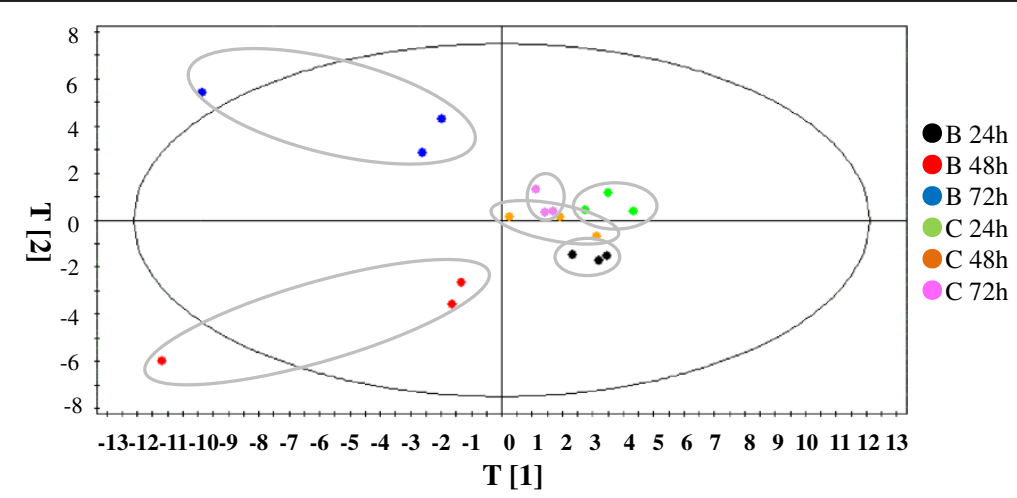

Figure 2 PCA score plot of metabolomic profiles of Synechocystis along the treatment time course. Samples with or without butanol treatments were indicated by different colors. The biological replicates were circled for the same conditions. 
Table 5 Differentially regulated metabolites *

\begin{tabular}{|c|c|c|c|}
\hline Metabolites & $24 \mathrm{~h}$ & $48 \mathrm{~h}$ & $72 \mathrm{~h}$ \\
\hline \multicolumn{4}{|l|}{ Cluster I } \\
\hline Aspartic acid & 4 & 9 & 9 \\
\hline Glycerol 1-phosphate & 7 & 9 & 6 \\
\hline 3-phosphoglycerate & 3 & 9 & 3 \\
\hline Citric acid & 2 & 9 & 6 \\
\hline D-allose & 9 & 3 & 9 \\
\hline Adenosine & 5 & 9 & 8 \\
\hline Urea & 1 & 7 & 3 \\
\hline \multicolumn{4}{|l|}{ Cluster II } \\
\hline Oxalic acid & 0 & 9 & 6 \\
\hline Glycine & 0 & 4 & 5 \\
\hline Succinic acid & 0 & 6 & 6 \\
\hline L-glutamic acid (dehydrated) & 0 & 9 & 6 \\
\hline Isocitric acid & 0 & 6 & 6 \\
\hline Myristic acid & 0 & 6 & 8 \\
\hline Sucrose & 0 & 6 & 9 \\
\hline \multicolumn{4}{|l|}{ Cluster III } \\
\hline 1,3 Propanediol & 6 & -6 & -6 \\
\hline L-alanine & 3 & -3 & -9 \\
\hline Itaconic acid & 9 & -4 & -9 \\
\hline Spermidine & 4 & -9 & -5 \\
\hline \multicolumn{4}{|l|}{ Cluster IV } \\
\hline Methyl palmitate & 9 & -5 & 6 \\
\hline Talose & 9 & -4 & 9 \\
\hline Benzene-1,2,4-triol & 2 & -3 & 6 \\
\hline Adrenaline & 7 & -6 & 9 \\
\hline Lauric acid & 9 & -8 & 7 \\
\hline \multicolumn{4}{|l|}{ Cluster V } \\
\hline L-threonine & 7 & 9 & 0 \\
\hline D-malic acid & 5 & 3 & 0 \\
\hline L-serine & 6 & 5 & 0 \\
\hline \multicolumn{4}{|l|}{ Cluster VI } \\
\hline L-pyroglutamic acid & -3 & -9 & -3 \\
\hline Linoleic acid & 7 & 0 & 9 \\
\hline L-(+) lactic acid & 2 & -6 & 0 \\
\hline Pyruvic acid & -6 & 0 & 9 \\
\hline 3-hydroxypyridine & 0 & -5 & 9 \\
\hline 4-hydroxypyridine & 0 & -3 & 8 \\
\hline Malonic acid & -5 & -3 & 8 \\
\hline Caprylic acid & -6 & 0 & 9 \\
\hline Octane & -2 & -5 & 8 \\
\hline Glycerol & 6 & -5 & 0 \\
\hline Glyceric acid & 8 & -9 & 0 \\
\hline Uracil & -8 & 6 & 4 \\
\hline
\end{tabular}

Table 5 Differentially regulated metabolites * (Continued)

\begin{tabular}{|c|c|c|c|}
\hline Putrescine & -8 & 0 & 2 \\
\hline Tagatose & -5 & 0 & 9 \\
\hline Palmitic acid & 0 & -6 & 5 \\
\hline Methyl stearate & -9 & 9 & 9 \\
\hline D-glucose-6-phosphate & -3 & 8 & 9 \\
\hline Stearic acid & 0 & -8 & 5 \\
\hline Arachidic acid & -3 & -8 & 5 \\
\hline D-(+) trehalose & -3 & 9 & 0 \\
\hline
\end{tabular}

The findings were consistent with early studies which showed 3-phosphoglycerate is increasingly withdrawn from the Calvin cycle in S. elongatus PCC 7942 under iron limitation stress [47]. In addition, phosphoglycerate kinase that catalyzes the production of 3-phosphoglycerate from 1,3-bisphosphoglycerate was also found induced in Anabaena sp. PCC7120 under arsenic stress [48]. Moreover, early study has shown that the intracellular levels of organic acids (glyceric, glycolic and glyoxylic acids) and amino acids (glycine and serine) were elevated in salt-treated Anabaena sp. PCC 7120 as compared to those in the control cells [49]. The results suggested that these metabolites could be important part of metabolic responses to both butanol and general environmental stresses.

Previous proteomic study found that a common stress response of Synechocystis under various environmental perturbations, irrespective of amplitude and duration, is the activation of atypical pathways for the acquisition of carbon and nitrogen from urea and arginine, as evidenced by the significant up-regulation of urease that converts urea into $\mathrm{CO}_{2}$ and ammonia, under most conditions [50]. Our metabolomic analysis showed that urea was induced by butanol, especially at 48 and $72 \mathrm{~h}$. Previous proteomic analysis showed that cyanophycinase, involved in the breakdown of cyanophycin, a storage molecule for excess carbon and nitrogen, into arginine and aspartic acid, was moderately up-regulated under several conditions [50]. Arginine and aspartic acid can be further converted to glutamate and succinate, respectively [51]. Metabolomic analysis showed that aspartic acid was significantly induced at all three time points, and succinic acid and L-glutamic acid were both induced at 48 and $72 \mathrm{~h}$ by butanol treatment. These results implied that a similar up-regulated degradation of cyanophycin may also occur under butanol stress.

Integrated transcriptomic and metabolomic analysis has been proposed as a powerful tool to build the relationship between information elements (i.e., genes/transcripts) and functional elements (i.e., metabolites) in cells $[25,52,53]$. 
In one recent study, integrated transcriptomic and metabolomic approach was used to determine the infection mechanism of Rhodococcus fascians into Arabidopsis thaliana. The transcriptomic analysis showed a significant impact of infection on the primary metabolism of the host, which was then confirmed by subsequent metabolite analysis, for example, invertase transcripts and activities strongly enhanced upon infection, may related to the increase in the hexose:sucrose ratio [54]. In another study to compare the aerobic and anaerobic fermentations of Zymomonas mobilis, researchers found that greater amounts of end products such as acetate, lactate and acetoin were detected under aerobic conditions, while no change in terms of gene expression was found between aerobic and anaerobic conditions in the early exponential growth phase [55], implying the importance to applying integrated technology in uncovering related molecular mechanism. In this study, although only small number of metabolites can be chemically classified in Synechocystis, the metabolomic analysis found increased abundances of aspartic acid and serine, which was consistent with the induction of slr0550 encoding dihydrodipicolinate synthase involved in aspartate pathway, and sll0455 encoding homoserine dehydrogenase involved in serine pathway, respectively (Table 5). In addition, increased abundance of glutamic acid inside the cells was correlated with upregulation of sll1883 encoding bifunctional ornithine acetyltransferase/ $\mathrm{N}$-acetylglutamate synthase protein, sll0461 encoding gamma-glutamyl phosphate reductase, slr0288 encoding glutamate--ammonia ligase, and slr1898 encoding acetylglutamate kinase that are involved in metabolism of glutamate family amino acids (Table 5). Moreover, metabolomic analysis showed the increased abundances of intermediates in the glycolysis pathway, such as glucose-6-P and 3-PG, consistent with the induction of two key genes, slr0752 encoding phosphopyruvate hydratase and sll0745 encoding 6-phosphofructokinase in the glycolysis pathway. Consistent with this result, upregulation of glycolysis has been reported for various microbes under stress condition [56,57]. In a recent ${ }^{13} \mathrm{C}$-based flux analysis, a thermophilic ethanol-tolerant Geobacillus thermoglucosidasius M10EXG was found to prefer glycolysis, the pentose phosphate pathway and the TCA cycle for glucose metabolism [58]. On the other hand, for some of differentially regulated metabolites identified, such as urea and cyanophycin, no change was observed for their functionally-related genes in the transcriptomic datasets, which may be due to multiple factors, such as the snapshot nature of the analysis and the different stability of RNA molecules [25]. Nevertheless, the results further demonstrated that transcriptomic and metabolomic technologies could be complementary to each other, allowing better decipherment of cellular responses of Synechocystis under butanol stress.

\section{Validation of potential tolerance targets}

Three genes, sll0690, slr0947 and slr1295 which were found induced by butanol exposure at all three time points (i.e. 24, 48 and $72 \mathrm{~h}$ ) (Table 2), were selected for construction of knockout mutants and for validation of their involvement in butanol resistance. sll0690 encoding a probable transcription regulator, was up-regulated 5-6 folds, slr0947 encoding an OmpR-type DNA-binding response regulator, was up-regulated 2.4-5.5 folds, and slr1295 encoding an iron transport system substratebinding protein was up-regulated 1.8-5.9 folds by butanol, respectively. Two corresponding proteins of the genes, Slr0947 and Slr1295, were identified in our previous proteomic analysis, in which they were also slightly upregulated 1.16-1.55 and 1.16-1.57 folds after butanol treatment for $48 \mathrm{~h}$, respectively [26]. After confirmed by PCR and sequencing, the mutants were grown in parallel with wild type Synechocystis in both normal BG11 medium and the BG11 medium supplemented with $0.25 \%(v / v)$ butanol. Comparative analysis showed that although there is no visible difference in terms of growth patterns between the wild type and all three mutants in the regular BG11 medium (Figure 3A), gene disruption of sll0690, slr0947 and slr1295 led to increased butanol sensitivity, suggesting they were involved in butanol resistance (Figure 3B). Currently little is known how these genes are involved in butanol tolerance, although early studies have found that the slr1295 gene product, a periplasm-located component of an iron transporter, has a function in protecting photosystem (PS) II [59] and was induced under saltstress condition [60]; and the slr0947 gene was involved in the regulation of the coupling of phycobilisomes to photosynthetic reaction centers, and reduction of the copy number of slr0947 resulted in decreased efficiency of energy transfer from phycobilisomes to photosystem II relative to photosystem I [61].

\section{Conclusions}

RNA-Seq based transcriptomics coupled with RT-PCR and GC-MS metabolomics were used to determine gene targets related to butanol tolerance in Synechocystis. Although the overall cellular responses revealed by transcriptomics and metabolomics were very similar to those revealed by our previous proteomic analysis, the genes/proteins involved in each type of responses were not always identical, consistent with recent conclusions that only a weak correlation exists between large-scale transcriptomic and proteomic datasets so that an integrative analysis of multiple levels of gene expression would be necessary and valuable [62]. A comprehensive transcriptomic and metabolomic analysis with proteomic analysis led to identification of putative gene targets which may be involved in butanol tolerance. By constructing $\mathrm{KO}$ mutants and analyzing their butanol resistance, we 

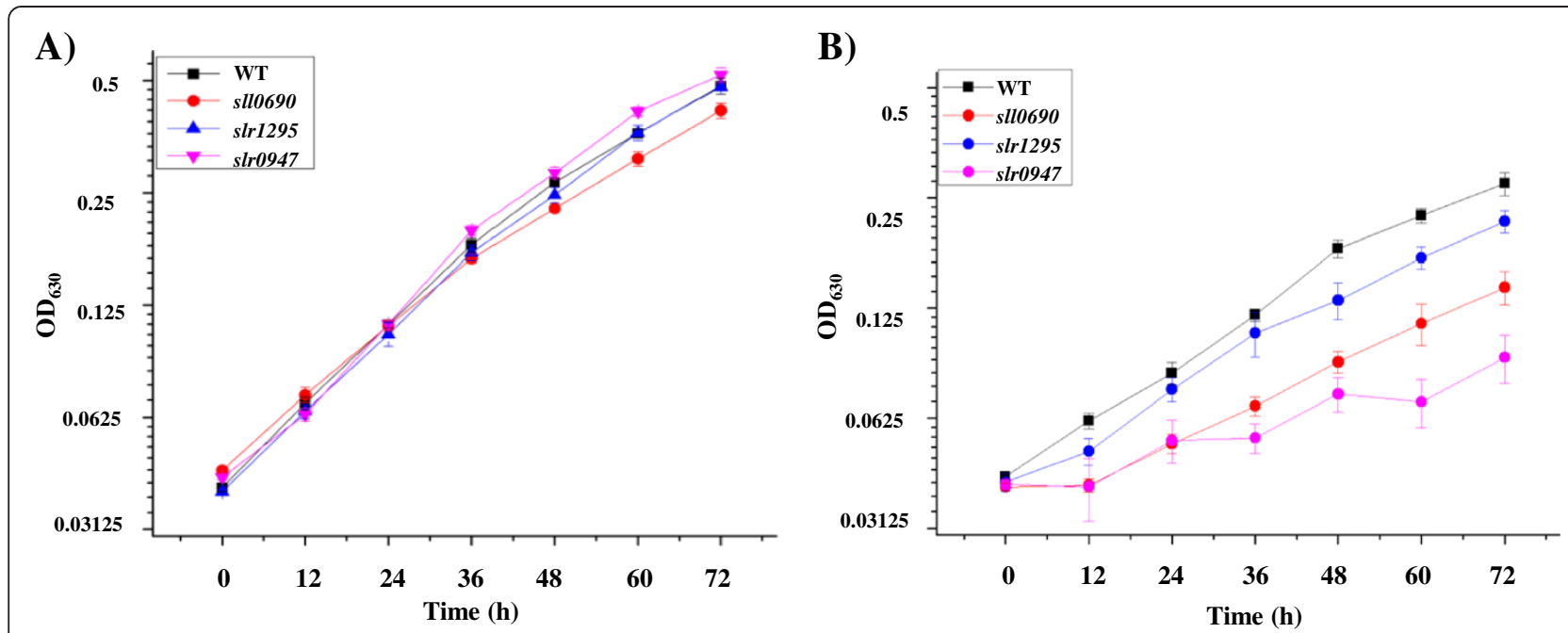

Figure 3 Comparative analysis of butanol tolerance of wild-type strain and mutants. A) Growth time courses of wild type, $\Delta$ s/l0690,

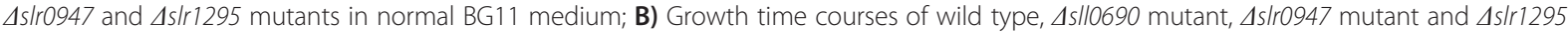
mutant in BG11 media supplemented with $0.25 \%(\mathrm{v} / \mathrm{V})$ butanol.

validated three potential gene targets identified by the integrated OMICS approaches. In the future, once further functional characterization of these candidate genes completed, it is possible they can serve as target genes to engineer more robust butanol-tolerant cyanobacterial hosts.

\section{Materials and methods}

Bacterial growth conditions and butanol treatment Synechocystis sp. PCC 6803 was grown in BG11 medium (pH 7.5) as described previously [26,27]. Butanol of 0.20\% $(v / v)$ was added at the beginning of cultivation. Cells were collected by centrifugation at $8,000 \times g$ for $10 \mathrm{~min}$ at $4^{\circ} \mathrm{C}$.

\section{RNA preparation and CDNA synthesis}

Approximately $10 \mathrm{mg}$ of cell pellets were frozen by liquid nitrogen immediately after centrifugation and cell walls were broken with mechanical cracking at low temperature. Cell pellets were then resuspended in Trizol reagent (Ambion, Austin, TX) and mixed well by vortex. Total RNA extraction was achieved using a miRNeasy Mini Kit (Qiagen, Valencia, CA). Contaminating DNA in RNA samples was removed with DNase I according to the instruction in the miRNeasy Mini Manual (Qiagen, Valencia, CA). The RNA quality and quantity were determined using Agilent 2100 Bioanalyzer (Agilent, Santa Clara, CA) and subjected to cDNA synthesis. The RNA integrity number (RIN) of every RNA sample used for sequencing was more than 8.0. For each sample, $500 \mathrm{ng}$ total RNA were subjected to cDNA synthesis using a NuGEN Ovation ${ }^{\circ}$ Prokaryotic RNA-Seq System according to manufacturer's protocol (NuGEN, San Carlos, CA). The resulting double-stranded cDNA was purified using the MinElute Reaction Cleanup Kit (Qiagen, Valencia, CA).

\section{RNA-seq library preparation}

The double-stranded cDNA obtained was subjected to library preparation using the Illumina TruSeqTM RNA Sample Preparation Kit (Illumina, San Diego, CA), through a four-step protocol of end repairing, adenylate 3' ends adding, adapter ligation, and cDNA template enrichment. To determine the quality of libraries, a Qubit ${ }^{\circ} 2.0$ Fluorometer and Qubit ${ }^{\text {tm }}$ dsDNA HS (Invitrogen, Grand Island, NY) were first used to determine the DNA concentration of the libraries, and then FlashGel DNA Cassette (Lonza, USA) or Agilent Technologies 2100 Bioanalyzer (Agilent, Santa Clara, CA) was used to determine the product size of the libraries, with good libraries typically around $300 \mathrm{bp}$.

\section{Next-generation sequencing}

RNA $2 \times 100$ bp paired-end sequencing was performed using Illumina's Solexa Genome Analyzer II using the standard protocol. The cDNA library of each sample was loaded to a single lane of an Illumina flow cell. The image deconvolution and calculation of quality value were performed using Goat module (Firecrest v.1.4.0 and Bustard v.1.4.0 programs) of Illumina pipeline v.1.4.

\section{Transcriptomics data analysis}

Sequence reads were pre-processed using FASTX Toolkit (v. 0.0.13) to remove low-quality bases, and reads shorter than $20 \mathrm{bp}$. The qualified sequence reads were then mapped to non-coding RNA ( $n c$ RNA) sequences using Bowtie (v. 2.0.0) with default settings. Genome sequences (including $n c$ RNA sequences) and annotation information of Synechocystis sp. PCC 6803 were downloaded from NCBI (Downloaded on April 22, 2012) [27]. Reads that 
mapped to $n c$ RNA sequences were excluded from further analysis in this study. For paired-end Illumina reads, both pairs were removed if either pair mapped to rRNA. Remaining reads were mapped to the Synechocystis genome using Bowtie (v. 2.0.0) with the default parameters. For gene expression determination, we performed a standard calculation of Reads Per Kilobase of Gene per Million Mapped Reads (RPKM) [63]. We performed comparative transcriptome analysis for all three time points (i.e., 24, 48 and 72 h). To identify the reliable gene targets related to butanol tolerance, only the genes with 1.5-fold induction by butanol at all three time points were regarded as up-regulated genes.

\section{Quantitative real-time RT-PCR analysis}

The identical RNA samples used for transcriptomics analysis as described above were used for RT-qPCR analysis. cDNAs were synthesized using RevertAidTM Reverse Transcriptase (Fermentas, Glen Burnie, MD). The qPCR reaction was carried out in $20 \mu \mathrm{l}$ reactions containing $10 \mu \mathrm{l}$ of SYBR ${ }^{\circ}$ Green PCR Master Mix (Applied Biosystems, Foster City, CA), and $2 \mu \mathrm{l}$ of each PCR primer at $2 \mathrm{mM}$, employing the StepOnePlus ${ }^{\mathrm{mm}}$ Real-Time PCR System (Applied Biosystems, Foster City, CA), under the following condition: $50^{\circ} \mathrm{C}$ for $2 \mathrm{~min}$ and $95^{\circ} \mathrm{C}$ for $10 \mathrm{~min}$, followed by 40 cycles of $95^{\circ} \mathrm{C}$ for $15 \mathrm{~s}$ and $60^{\circ} \mathrm{C}$ for $1 \mathrm{~min}$. Quantification of gene expression was determined according to standard process of RT-PCR which used serial dilutions of known concentration of chromosome DNA as template to make a standard curve. The $\operatorname{rnpB}$ gene (6803 s01) encoding RNase P subunit B was used as an internal control according to the previous publication [64]. Three technical replicates were performed for each gene. Data analysis was carried out using the StepOnePlus analytical software (Applied Biosystems, Foster City, CA). Data was presented as ratios of the amount of normalized transcript in the treatment to that from the control. The gene ID and their related primer sequences used for real-time RT-PCR analysis were listed in Additional file 1: Table S1.

\section{GC-MS based metabolomics analysis}

All chemicals used for metabolome isolation and GC/MS analysis were obtained from Sigma-Aldrich (Taufkirchen, Germany). Cells were collected from control and butanoltreated $(0.2 \% \mathrm{v} / \mathrm{v})$ cultures at 24,48 and $72 \mathrm{~h}$, respectively. Three biological replicates were established for each sample, and every sample was analyzed three times. For each sample, cells from 5 to $20 \mathrm{~mL}$ culture, equivalent to $10^{8}$ cells $\mathrm{mL}^{-1}$, were collected by centrifugation at $8000 \times g$ for $10 \mathrm{~min}$ at $4^{\circ} \mathrm{C}$ (Eppendorf 5430R, Hamburg, Germany). The cell pellets were frozen in liquid nitrogen and then stored at $-80^{\circ} \mathrm{C}$ before use. $i$ ) Metabolome extraction: cells were re-suspended in $1 \mathrm{~mL}$ cold 10:3:1 $(v / v / v)$ methanol: chloroform: $\mathrm{H}_{2} \mathrm{O}$ solution (MCW), and frozen in liquid nitrogen and thawed for five times. Supernatants were collected by centrifugation at $14,000 \times g$ for $3 \mathrm{~min}$ at $4^{\circ} \mathrm{C}$ (Eppendorf 5430R, Hamburg, Germany). To normalize variations across samples, an internal standard (IS) solution $(100 \mu \mathrm{g} / \mathrm{mL} \mathrm{U}$ - 13C-sorbitol, $5 \mu \mathrm{L})$ was added to $100 \mu \mathrm{L}$ supernatant in a $1.5-\mathrm{mL}$ microtube before it was dried by vacuum centrifugation for $2-3 \mathrm{~h}\left(4^{\circ} \mathrm{C}\right)$. ii) Sample derivatization: derivatization was conducted according to the twostage technique by Roessner et al. (2001) [65]. The samples were dissolved in $10 \mu \mathrm{L}$ methoxyamine hydrochloride (40 $\mathrm{mg} / \mathrm{mL}$ in pyridine) and shaken at $30^{\circ} \mathrm{C}$ for $90 \mathrm{~min}$, then were added with $90 \mu \mathrm{L} \mathrm{N}$-methyl- $\mathrm{N}$-(trimethylsilyl) trifluoroacetamide (MSTFA) and incubated at $37^{\circ} \mathrm{C}$ for $30 \mathrm{~min}$ to trimethylsilylate the polar functional groups. The derivate samples were collected by centrifugation at $14,000 \times g$ for $3 \mathrm{~min}$ before GC/MS analysis. iii) GCMS analysis: sample analysis was performed on a GC-MS system-GC 7890 coupled to an MSD 5975 (Agilent Technologies, Inc., Santa Clara, CA, USA) equipped with a HP-5MS capillary column $(30 \mathrm{~m} \times 250 \mathrm{~mm}$ id). $2 \mu \mathrm{L}$ derivatized sample was injected in splitless mode at $230^{\circ} \mathrm{C}$ injector temperature. The $\mathrm{GC}$ was operated at constant flow of $1 \mathrm{~mL} / \mathrm{min}$ helium. The temperature program started isocratic at $45^{\circ} \mathrm{C}$ for $2 \mathrm{~min}$, followed by temperature ramping of $5^{\circ} \mathrm{C} / \mathrm{min}$ to a final temperature of $280^{\circ} \mathrm{C}$, and then held constant for additional $2 \mathrm{~min}$. The range of mass scan was $\mathrm{m} / \mathrm{z} 38-650$. iv) Data processing and statistical analysis: The mass fragmentation spectrum was analyzed using the Automated Mass Spectral Deconvolution and Identification System (AMDIS) [66] to identify the compounds by matching the data with Fiehn Library [67] and the mass spectral library of the National Institute of Standards and Technology (NIST). Peak areas of all identified metabolites were normalized against the internal standard and the acquired relative abundances for each identified metabolite were used for future data analysis.

All metabolomic profile data was first normalized by internal control and cell numbers, and then subjected to Principal Component Analysis using software SIMCA-P 11.5 [68]. Differentially regulated metabolites were determined using a threshold of fold change greater than 1.5 between butanol-treated samples and controls. For each time point, three biological replicates of butanol-treated samples were compared with three biological replicates of control, generating 9 ratios. For each ratio, $r>1.5$ was assigned as " +1 ", $r<-1.5$ as " -1 ", and $-1.5<r<1.5$ as "0". The sums of the nine ratios for each metabolite at any time point were provided in Table 5 .

\section{Construction and analysis of knockout mutants}

A fusion PCR based method was employed for the construction of gene knockout fragments [69]. Briefly, for the gene target selected, three sets of primers were designed to amplify a linear DNA fragment containing 
the chloramphenicol resistance cassette (amplified from a plasmid pACYC184) with two flanking arms of DNA upstream and downstream of the targeted gene. The linear fused PCR amplicon was used directly for transformation into Synechocystis by natural transformation. The chloramphenicol-resistant transformants were obtained and passed several times on fresh BG11 plates supplemented with $10 \mu \mathrm{g} / \mathrm{ml}$ chloramphenicol to achieve complete chromosome segregation. Three genes, sll0690, slr0947 and slr1295 that have been found differentially regulated by butanol exposure, were selected for construction of gene knockout mutants. PCR primers for mutant construction and validation were listed in Additional file 1: Table S1. Full segregation for sll0690 and slr1295 genes was confirmed by PCR. For $\Delta s l r 0947$ mutant, we found that it contained trace amount of original wild-type band in the DNA gels even after more than ten passages, it may worth further investigation whether slr0947 is a lethal gene for the condition. Comparative growth analysis of the wild type 6803 and the mutants were performed in 100-mL flasks each with $10 \mathrm{~mL} \mathrm{BG11} \mathrm{medium} \mathrm{with} \mathrm{or} \mathrm{without} 0.25 \%$ $(v / v)$ butanol. Cultivation conditions are the same as described above. Growth analysis was performed in biological triplicates.

\section{Additional file}

Additional file 1: Table S1. Primers for RT-PCR analysis and mutant construction.

\section{Abbreviations \\ GC-MS: Gas chromatography-Mass spectrometry; Glucose-6-P: glucose- 6-phosphate; iTRAQ: Isobaric tag for relative and absolute quantitation; LC-MS/MS: Liquid chromatography-tandem mass spectrometry; ncRNA: non-coding RNA; PCA: Principal component analysis; 3-PG: 3-phosphoglycerate; RPKM: Reads per kilobase of gene per million mapped reads; ROS: Reactive oxygen species; RT-PCR: Reverse-transcript PCR.}

\section{Competing interests}

The authors declare no competing interests.

\section{Authors' contributions}

$X R, Z S$, LC and JW carried out cultivation and transcriptomics analysis. LC, XR, ZS and $J$ carried out the RT-PCR, mutant construction and phenotypic analysis. HZ, LC, JW, JQ and WZ finished the statistical analysis for transcripomic data. MS, XT, LC and WZ carried out the metabolomics experiments and analysis. LC, JW and WZ conceived of the study, participated in its design and coordination. HZ, JW, LC and WZ drafted the manuscript. All authors read and approved the final manuscript.

\footnotetext{
Acknowledgements

The research was supported by grants from National Basic Research Program of China ("973" program, project No. 2011CBA00803 and No. 2012CB721101) and National High-tech R\&D Program ("863" program, project No. 2012AA02A707). The authors would also like to thank Tianjin University and the "985 Project" of Ministry of Education for their generous supports in establishing the research laboratory.
}

Received: 6 April 2013 Accepted: 23 July 2013

Published: 25 July 2013

\section{References}

1. Durre P: Biobutanol: an attractive biofuel. Biotechnol J 2007, 2:1525-1534.

2. Durre P: Fermentative butanol production: bulk chemical and biofuel. Ann NY Acad Sci 2008, 1125:353-362.

3. Durre P, Fischer RJ, Kuhn A, Lorenz K, Schreiber W, Sturzenhofecker B, Ullmann S, Winzer K, Sauer U: Solventogenic enzymes of Clostridium acetobutylicum: catalytic properties, genetic organization, and transcriptional regulation. FEMS Microbiol Rev 1995, 17:251-262.

4. Lee SY, Park JH, Jang SH, Nielsen LK, Kim J, Jung KS: Fermentative butanol production by Clostridia. Biotechnol Bioeng 2008, 101:209-228.

5. Ezeji TC, Qureshi N, Blaschek H: Acetone-butanol-ethanol production from concentrated substrate: reduction in substrate inhibition by fed-batch technique and product inhibition by gas stripping. Appl Micriobiol Biotechnol 2004, 63:653-658.

6. Ezeji TC, Qureshi N, Blaschek HP: Butanol fermentation research: upstream and downstream manipulations. Chem Rec 2004, 4:305-314.

7. Zheng YN, Li LZ, Xian M, Ma YJ, Yang JM, Xu X, He DZ: Problems with the microbial production of butanol. J Ind Microbiol Biotechnol 2009, 36:1127-1138.

8. Lutke-Eversloh T, Bahl H: Metabolic engineering of Clostridium acetobutylicum: recent advances to improve butanol production. Curr Opin Biotechnol 2011, 22:634-647.

9. Zhu XG, Long SP, Ort DR: Improving photosynthetic efficiency for greater yield. Annu Rev Plant Biol 2010, 61:235-261.

10. Machado IM, Atsumi S: Cyanobacterial biofuel production. J Biotechnol 2012, 162:50-56

11. Atsumi S, Higashide W, Liao J: Direct photosynthetic recycling of carbon dioxide to isobutyraldehyde. Nat Biotechnol 2009, 27:1177-1180.

12. Lan E, Liao J: Metabolic engineering of cyanobacteria for 1-butanol production from carbon dioxide. Metab Eng 2011, 13:353-363.

13. Atsumi S, Cann AF, Connor MR, Shen CR, Smith KM, Brynildsen MP, Chou KJ, Hanai T, Liao JC: Metabolic engineering of Escherichia coli for 1-butanol production. Metab Eng 2008, 10:305-311.

14. Inui M, Suda M, Kimura S, Yasuda K, Suzuki H, Toda H, Yamamoto S, Okino S, Suzuki N, Yukawa H: Expression of Clostridium acetobutylicum butanol synthetic genes in Escherichia coli. Appl Microbiol Biotechnol 2008, 77:1305-1316.

15. Shen CR, Liao JC: Metabolic engineering of Escherichia coli for 1-butanol and 1-propanol production via the keto-acid pathways. Metab Eng 2008, 10:312-320

16. Nicolaou SA, Gaida SM, Papoutsakis ET: A comparative view of metabolite and substrate stress and tolerance in microbial bioprocessing: From biofuels and chemicals, to biocatalysis and bioremediation. Metab Eng 2010, 12:307-331.

17. Dunlop MJ: Engineering microbes for tolerance to next-generation biofuels. Biotechnol Biofuels 2011, 4:32.

18. Papoutsakis ET: Engineering solventogenic clostridia. Curr Opin Biotechnol 2008, 19:420-429.

19. Ezeji T, Milne C, Price ND, Blaschek HP: Achievements and perspectives to overcome the poor solvent resistance in acetone and butanol-producing microorganisms. Appl Microbiol Biotechnol 2010, 85:1697-1712.

20. Liyanage $H$, Young $M$, Kashket ER: Butanol tolerance of Clostridium beijerinckii NCIMB 8052 associated with down-regulation of gldA by antisense RNA. J Mol Microbiol Biotechnol 2000, 2:87-93.

21. Jia K, Zhang Y, Li Y: Identification and Characterization of two functionally unknown genes involved in butanol tolerance of Clostridium acetobutylicum. PLoS One 2012, 7:e38815.

22. Zhang $\mathrm{H}$, Chong $\mathrm{H}$, Ching $\mathrm{CB}$, Song $\mathrm{H}$, Jiang R: Engineering global transcription factor cyclic AMP receptor protein of Escherichia coli for improved 1-butanol tolerance. Appl Microbiol Biotechnol 2012, 94:1107-1117.

23. Atsumi S, Wu TY, Machado IMP, Huang WC, Chen PY, Pellegrini M, Liao JC: Evolution, genomic analysis, and reconstruction of isobutanol tolerance in Escherichia coli. Mol Syst Biol 2010, 6:449.

24. Reyes LH, Almario MP, Kao KC: Genomic library screens for genes involved in n-butanol tolerance in Escherichia coli. PLoS One 2011, 6(3):e17678.

25. Zhang W, Li F, Nie L: Integrating multiple 'omics' analysis for microbial biology: application and methodologies. Microbiology 2010, 156:287-301.

26. Tian XX, Chen L, Wang JX, Qiao J, Zhang WW: Quantitative proteomics reveals dynamic responses of Synechocystis sp. PCC 6803 to next-generation biofuel butanol. J Proteomics 2012, 78:326-345.

27. Kaneko T, Nakamura Y, Sasamoto S, Watanabe A, Kohara M, Matsumoto M, Shimpo S, Yamada M, Tabata S: Structural analysis of four large plasmids 
harboring in a unicellular cyanobacterium, Synechocystis sp. PCC 6803. DNA Res 2003, 10:221-228.

28. Noone D, Howell A, Collery R, Devine KM: YkdA and YvtA, HtrA-like serine proteases in Bacillus subtilis, engage in negative autoregulation and reciprocal cross-regulation of $y k d A$ and $y v t A$ gene expression. J Bacteriol 2001, 183:654-663.

29. Snider J, Gutsche I, Lin M, Baby S, Cox B, Butland G, Greenblatt J, Emili A, Houry WA: Formation of a distinctive complex between the inducible bacterial lysine decarboxylase and a novel AAA + ATPase. J Biol Chem 2006, 281:1532-1546.

30. Dieppedale J, Sobral D, Dupuis M, Dubail I, Klimentova J, Stulik J, Postic G, Frapy E, Meibom KL, Barel M, Charbit A: Identification of a putative chaperone involved in stress resistance and virulence in Francisella tularensis. Infect Immun 2011, 79:1428-1439.

31. Rutherford BJ, Dahl RH, Price RE, Szmidt HL, Benke PI, Mukhopadhyay A, Keasling JD: Functional genomic study of exogenous $n$-butanol stress in Escherichia coli. Appl Environ Microbiol 2010, 76:1935-1945.

32. Das PK, Bagchi SN: Role of bacterioferritin comigratory protein and glutathione peroxidase-reductase system in promoting bentazone tolerance in a mutant of Synechococcus elongatus PCC7942. Protoplasma 2012, 249:65-74

33. Kim HG, Kim BC, Park EH, Lim CJ: Stress-dependent regulation of a monothiol glutaredoxin gene from Schizosaccharomyces pombe. Can J Microbiol 2005, 51:613-620.

34. Pujol-Carrion N, De la Torre-Ruiz MA A: Glutaredoxins Grx4 and Grx3 of Saccharomyces cerevisiae play a role in actin dynamics through their Trx domains, which contributes to oxidative stress resistance. Appl Environ Microbiol 2010, 76:7826-7835

35. Qiao JJ, Wang JX, Chen L, Tian XX, Zhang WW: Quantitative iTRAQ LC-MS/MS proteomics reveals metabolic response to biofuel ethanol in cyanobacterial Synechocystis sp. PCC 6803. J Proteome Res 2012, 11(11):5286-5300.

36. Zhang W, Culley DE, Hogan M, Vitirit L, Brockman FJ: Oxidative stress and heat-shock responses in Desulfovibrio vulgaris by genome-wide transcriptomic analysis. Antonie Van Leeuwenhoek 2006, 90:41-55.

37. Moskovitz J, Berlett B, Poston JM, Stadtman ER: The yeast peptide-methionine sulfoxide reductase functions as an antioxidant in vivo. Proc Natl Acad SCi USA 1997, 94:9585-9589.

38. Moskovitz J, Lescher E, Berlett BS, Azare J, Poston JM, Stadtman ER: Over-expression of peptide-methionine sulfoxide reductase in Saccharomyces cerevisiae and human T cells provides them with high resistance to oxidative stress. Proc Natl Acad Sci USA 1998, 95:14071-14075.

39. Truong-Bolduc QC, Ding Y, Hooper DC: Posttranslational modification influences the effects of MgrA on norA expression in Staphylococcus aureus. J Bacteriol 2008, 190:7375-7381.

40. Economou A: Bacterial protein translocase: a unique molecular machine with an army of substrates. FEBS Lett 2000, 476:18-21.

41. Cline K, McCaffery M: Evidence for a dynamic and transient pathway through the TAT protein transport machinery. EMBO J 2007, 26:3039-3049.

42. von Wobeser E, Ibelings BW, Bok J, Krasikov V, Huisman J, Matthijs HCP: Concerted changes in gene expression and Cell physiology of the cyanobacterium Synechocystis sp. Strain PCC 6803 during transitions between nitrogen and light-limited growth. Plant Physiol 2011, 155:1445-1457.

43. Kadouri D, Jurkevitch E, Okon Y, Castro-Sowinski S: Ecological and agricultural significance of bacterial polyhydroxyalkanoates. Crit Rev Microbiol 2005, 31:55-67.

44. Kolodny NH, Bauer D, Bryce K, Klucevsek K, Lane A, Medeiros L, Mercer W, Moin S, Park D, Petersen J, Wright J, Yuen C, Wolfson AJ, Allen MM: Effect of nitrogen source on cyanophycin synthesis in Synechocystis sp. strain PCC 6308. J Bacteriol 2006, 188:934-940.

45. Schäfer L, Sandmann M, Woitsch S, Sandmann G: Coordinate up-regulation of carotenoid biosynthesis as a response to light stress in Synechococcus PCC7942. Plant Cell Environ 2006, 29:1349-1356.

46. Sandesh Kamath B, Vidhyavathi R, Sarada R, Ravishankar GA: Enhancement of carotenoids by mutation and stress induced carotenogenic genes in Haematococcus pluvialis mutants. Bioresour Technol 2008, 99:8667-8673.

47. Nodop A, Pietsch D, Höcker R, Becker A, Pistorius EK, Forchhammer K, Michel KP: Transcript profiling reveals new insights into the acclimation of the mesophilic fresh-water cyanobacterium Synechococcus elongatus PCC 7942 to iron starvation. Plant Physiol 2008, 147:747-763.

48. Pandey S, Rai R, Rai LC: Proteomics combines morphological, physiological and biochemical attributes to unravel the survival strategy of Anabaena sp. PCC7120 under arsenic stress. J Proteomics 2012, 75:921-937.
49. Srivastava AK, Alexova R, Jeon YJ, Kohli GS, Neilan BA: Assessment of salinity-induced photorespiratory glycolate metabolism in Anabaena sp. PCC 7120. Microbiology 2011, 157:911-917.

50. Wegener KM, Singh AK, Jacobs JM, Elvitigala T, Welsh EA, Keren N, Gritsenko MA, Ghosh BK, Camp DG 2nd, Smith RD, Pakrasi HB: Global proteomics reveal an atypical strategy for carbon/nitrogen assimilation by a cyanobacterium under diverse environmental perturbations. Mol Cell Proteomics 2010, 9:2678-2689.

51. Quintero MJ, Muro-Pastor AM, Herrero A, Flores E: Arginine catabolism in the cyanobacterium Synechocystis sp. Strain PCC 6803 involves the urea cycle and arginase pathway. J Bacteriol 2000, 182:1008-1015.

52. Urbanczyk-Wochniak E, Luedemann A, Kopka J, Selbig J, Roessner-Tunali U, Willmitzer L, Fernie AR: Parallel analysis of transcript and metabolic profiles: a new approach in systems biology. EMBO Rep 2003, 4:989-993.

53. Urbanczyk-Wochniak E, Willmitzer L, Fernie AR: Integrating profiling data: using linear correlation to reveal coregulation of transcript and metabolites. Methods Mol Biol 2007, 358:77-85.

54. Depuydt S, Trenkamp S, Fernie AR, Elftieh S, Renou JP, Vuylsteke M, Holsters $M$, Vereecke $D:$ An integrated genomics approach to define niche establishment by Rhodococcus fascians. Plant Physiol 2009, 149:1366-1386.

55. Yang S, Tschaplinski TJ, Engle NL, Carroll SL, Martin SL, Davison BH, Palumbo AV, Rodriguez M Jr, Brown SD: Transcriptomic and metabolomic profiling of Zymomonas mobilis during aerobic and anaerobic fermentations. BMC Genomics 2009, 10:34.

56. Chaussee MA, McDowell EJ, Rieck LD, Callegari EA, Chaussee MS: Proteomic analysis of a penicillin-tolerant $r g g$ mutant strain of Streptococcus pyogenes. J Antimicrob Chemother 2006, 58:752-759.

57. Guo W, Hao H, Dai M, Wang Y, Huang L, Peng D, Wang X, Wang H, Yao M, Sun Y, Liu Z, Yuan Z: Development of quinoxaline 1, 4-dioxides resistance in Escherichia coli and molecular change under resistance selection. PLoS One 2012, 7:e43322

58. Tang YJ, Sapra R, Joyner D, Hazen TC, Myers S, Reichmuth D, Blanch H, Keasling JD: Analysis of metabolic pathways and fluxes in a newly discovered thermophilic and ethanol-tolerant Geobacillus strain. Biotechnol Bioeng 2009, 102:1377-1386.

59. Tölle J, Michel KP, Kruip J, Kahmann U, Preisfeld A, Pistorius EK: Localization and function of the IdiA homologue SIr1295 in the cyanobacterium Synechocystis sp. strain PCC 6803. Microbiology 2002, 148:3293-3305.

60. Huang F, Fulda S, Hagemann M, Norling B: Proteomic screening of salt-stress-induced changes in plasma membranes of Synechocystis sp. strain PCC 6803. Proteomics 2006, 6:910-920.

61. Ashby MK, Mullineaux CW: Cyanobacterial ycf27 gene products regulate energy transfer from phycobilisomes to photosystems I and II. FEMS Microbiol Lett 1999, 181:253-260.

62. Nie L, Wu G, Culley DE, Scholten JC, Zhang W: Integrative analysis of transcriptomic and proteomic data: challenges, solutions and applications. Crit Rev Biotechnol 2007, 27:63-75.

63. Anders S, Huber W: Differential expression analysis for sequence count data. Genome Biol 2010, 11:R106.

64. Kloft N, Rasch G, Forchhammer K: Protein phosphatase PphA from Synechocystis sp. PCC 6803: the physiological framework of PII-P dephosphorylation. Microbiology 2005, 151:1275-1283.

65. Roessner U, Luedemann A, Brust D, Fiehn O, Linke T, Willmitzer L, Fernie A: Metabolic profiling allows comprehensive phenotyping of genetically or environmentally modified plant systems. Plant Cell 2001, 13:11-29.

66. Stein SE: An integrated method for spectrum extraction and compound identification from GC/MS data. Mass Spectrom 1999, 10(8):770-781.

67. Fiehn O: Metabolomics-the link between genotypes and phenotypes. Plant Mol Biol 2002, 48:155-171

68. Laiakis EC, Morris GA, Fornace AJ, Howie SR: Metabolomic analysis in severe childhood pneumonia in the Gambia, West Africa: findings from a pilot study. PLoS One 2010, 5(9):e12655.

69. Wang HL, Postier BL, Burnap RL: Optimization of fusion PCR for in vitro construction of gene knockout fragments. Biotechniques 2002, 33(26):28-30.

\section{doi:10.1186/1754-6834-6-106}

Cite this article as: Zhu et al.: Integrated OMICS guided engineering of biofuel butanol-tolerance in photosynthetic Synechocystis sp. PCC 6803. Biotechnology for Biofuels 2013 6:106. 